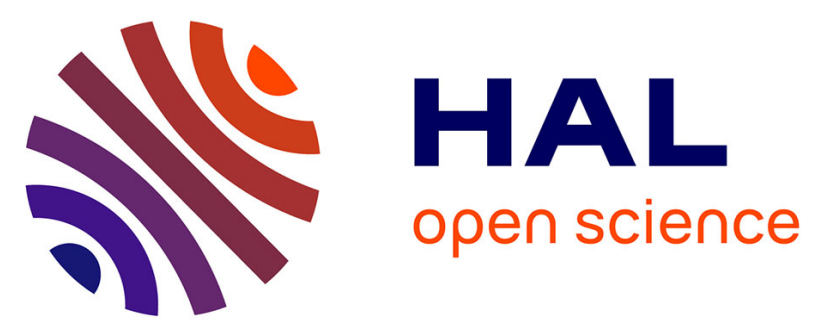

\title{
On the Black Start of Offshore Wind Power Plants with Diode Rectifier based HVDC Transmission
}

\author{
R. Ramachandran, S. Poullain, A. Benchaib, S. Bacha, Bruno François
}

\section{To cite this version:}

R. Ramachandran, S. Poullain, A. Benchaib, S. Bacha, Bruno François. On the Black Start of Offshore Wind Power Plants with Diode Rectifier based HVDC Transmission. 2019 21st European Conference on Power Electronics and Applications (EPE '19 ECCE Europe), Sep 2019, Genova, Italy. 10.23919/EPE.2019.8914779 . hal-03269044

\section{HAL Id: hal-03269044 https://hal.science/hal-03269044}

Submitted on 23 Jun 2021

HAL is a multi-disciplinary open access archive for the deposit and dissemination of scientific research documents, whether they are published or not. The documents may come from teaching and research institutions in France or abroad, or from public or private research centers.
L'archive ouverte pluridisciplinaire HAL, est destinée au dépôt et à la diffusion de documents scientifiques de niveau recherche, publiés ou non, émanant des établissements d'enseignement et de recherche français ou étrangers, des laboratoires publics ou privés. 
On the Black Start of Offshore Wind Power Plants with Diode Rectifier based HVDC Transmission

R. Ramachandran, S. Poullain, Abdelkrim Benchaib, Bacha Seddik \& Bruno Francois Proceeding of EPE'19 ECCE Europe, 2-6 Sept. 2018 , Genova, Italy

Preliminary version 


\title{
On the Black Start of Offshore Wind Power Plants with Diode Rectifier based HVDC Transmission
}

\author{
R. Ramachandran ${ }^{1,2}$, S. Poullain ${ }^{1}$, A. Benchaib ${ }^{1}$, S. Bacha $^{1,3}$, B. Francois ${ }^{2}$ \\ ${ }^{1}$ SuperGrid Institute, 69628, Villeurbanne, France. \\ ${ }^{2}$ L2EP, Univ. Lille, Centrale Lille, Arts et Métiers Paris Tech, HEI, EA 2697-L2EP, \\ Laboratory of Electrical Engineering and Power electronics, F-59000 Lille, France. \\ ${ }^{3}$ Univ. Grenoble Alpes, CNRS, Grenoble INP*, G2Elab, 38000, Grenoble, France. \\ E-Mail: ragavendran.ramachandran@supergrid-institute.com
}

\section{Keywords}

«Wind energy», « Renewable energy systems», « Power management», «HVDC»

\section{Acknowledgements}

This work is supported by the French Government under the program Investissements d'Avenir (ANEITE-002-01).

\begin{abstract}
This paper attempts a detailed comparison of some of the solutions for the black start of the Offshore Wind Power Plants with Diode Rectifier based HVDC transmission. The major challenges and control requirements to ensure the black start operation are explained following a brief review of the existing capabilities of wind generators. The various solutions surveyed as part of the study are presented along with a detailed comparison. Moreover, a case study is simulated, supported by calculations to highlight the power requirements of the offshore grid during black start, enabling further assessment of the black start solutions discussed.
\end{abstract}

\section{Introduction}

The Diode Rectifier (DR) based HVDC transmission for Offshore Wind Power Plants (OWPPs) or the DR-HVDC technology has multiple advantages over the Voltage Source Converter (VSC) based HVDC transmission, like reduction of costs, foot print and losses [1]. But, various challenges are introduced, for instance, the control of the Wind Generator (WG) Converters may need to be modified to regulate voltage and frequency of the offshore grid. Various solutions have been proposed for grid forming and power control of DR-HVDC OWPPs in [2]-[4] and they were reviewed and compared in [5]. Some of these studies have also been extended to the fault assessments in the offshore grid, DC link and the onshore grid [6]-[8].

The existing industrial solution for black start of the OWPP with DR-HVDC connection, is a Medium Voltage AC (MVAC) cable, extending from onshore AC grid (see Fig. 2). With the commitment by the European Union to reach at least $32 \%$ renewable energy mix by 2030 [9], generators like OWPPs can be expected by the relevant national Transmission System Operators (TSOs), to have the capability to self-start and further to provide system restoration services to the Onshore AC grid [10]. For this capability, the OWPPs need to black start without the aid of external sources - like the Onshore AC grid. The term 'black start' in this paper refers to energizing the offshore AC grid and the WGs (supplying the auxiliaries) to allow their operation. For DR-HVDC based OWPP, a black start alternative to the MVAC cable could lead to reduced costs and prevent relying completely on the onshore AC grid. A more recent publication for grid forming solution [4] mentions the use of energy storage at the WG level to enable the black start, but has not discussed in detail the strategy / solution in place. Other research works related to the DR-HVDC OWPP control either use MVAC Umbilical or do not directly address the black start problem. 
This paper discusses various solutions possible to ensure the black start of the offshore AC grid, some from the existing literature, while others being extensions of known concepts. The OWPP is assumed to be composed of Type 4 Wind Generator (WG) with Permanent Magnet Synchronous Generators (PMSGs), as is the case with recent research works that have proposed grid forming and power control solutions. These black start solutions are analyzed in detail considering the requirements of the offshore grid. The discussion of black start (or system restoration) of the onshore AC Grid by the OWPPs is beyond the scope of this paper. A detailed analysis with regards to energy requirements using a study case has been done to facilitate further assessment of the solutions. The following section provides a brief background on black start and the control requirements and also a review of the self-start capabilities of today's WGs.

\section{The black start of the offshore AC grid}

\section{Context}

Usually for OWPP with Voltage Source Converter (VSC) based HVDC transmission, the start-up of the offshore grid is performed by a Diesel generator located at the offshore platform and/or by using the offshore VSC by drawing required energy from the onshore grid through the HVDC link. The latter option demands a reliable onshore AC grid.

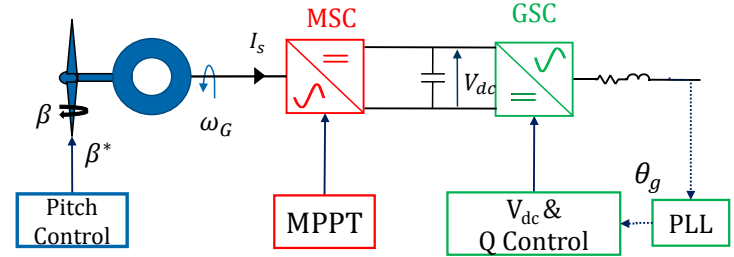

(a)

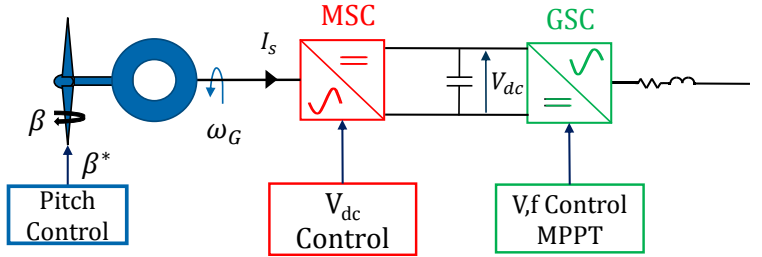

(b)

Fig. 1 : Control Schemes for the WGs (a) Grid Following Mode with VSC-HVDC (b) Grid Forming mode with DR-HVDC

In recent years, most of the larger machines rated above $6 \mathrm{MW}$ capacity are Type 4 equipped with Permanent Magnet Synchronous Generator (PMSG) and so the analysis presented in this paper is done considering OWPP with Type 4 PMSGs.

In the DR-HVDC based OWPPs, the WGs should have the grid forming capability i.e. distributed voltage and frequency regulation of the offshore grid (as pointed out in [2], [4]). In this case, the Machine Side Converter (MSC) of the WG controls the DC link voltage of the back to back converters and the Grid Side Converter (GSC) performs maximum power point tracking (MPPT) along with the regulation of offshore grid voltage and frequency. The stark difference in control functions for the MSC and GSC is illustrated in Fig. 1.

Considering the black start of the offshore grid, the energy requirements can be designated as twofold:

1. The power requirement of the auxiliaries of the WGs - the pitch and yaw drives, cooling systems, nacelle / tower lights and control systems among other equipment. Although there could be a small amount of reactive power requirement involved, these loads are deemed predominantly active.

2. The reactive power load of the AC marine cables (predominantly capacitive), offshore transformer(s), WG transformers along with resistive power losses (i.e. small active power load).

The auxiliaries of the WGs could be modelled as constant power loads, assuming variations corresponding to the use of pitch or yaw operations are minimum. Enabling the black start and island operation of the DR-HVDC OWPP involves the following challenges

1. Power supply to the WG auxiliary equipment with a reduced power production by the WGs. This active power requirement is estimated to be $1-5 \%$ [11] of the WG capacity and the pitch 
and the yaw motors require a fraction of this power to enable the controlled extraction of wind power. Two different cases are identified regarding the control of power output

a. Low or medium wind condition where the power set point can be altered with the control of electromagnetic torque and the use of pitch angle control of the turbine blades.

b. Wind speeds above rated speed where pitch control has to be employed (sometimes excessively) to reduce power production.

2. The offshore network equipment like the submarine cables and the WG transformers and the offshore transformer(s) have to be energized. Especially for the offshore collection network, the total active power losses are relatively less compared to the reactive power demand [12]. The WG inverters or the black start source should be able to support the inrush current of transformers among other losses and compensate the reactive power injection due to the submarine cables.

3. Once individual WGs are self-sustaining and the network equipment are energized, the offshore grid has to be maintained in island mode, with a synchronous operation of WGs with controlled AC voltage and frequency.

4. Since the HVDC voltage is already set to its rated value by the onshore VSC, offshore AC voltage has to be regulated in a coordinated manner, to a sufficient value to enable the DR conduction and wind power extraction. Islanding capability is also necessary in cases of faults in the HVDC link or the onshore AC grid.

\section{Black Start capability of Wind Generators - a Brief Review}

In [11] many inventions and research works that ensure black start or self-start capability of the wind generators in general have been reviewed. Although the focus in [11] and [13] has been the restoration of the onshore grid by the OWPPs, they provide valuable insight on existing technologies and research. Based on the existing technologies and literature, some of the major energy sources used for self-starting the wind generators are listed below

1. Diesel generator - which is more of a classical but a tried and tested solution

2. Battery storage - already part of the wind generator system or designed for the purpose

3. Using the wind energy itself (with support from energy source 1 or 2 ) to power neighboring wind generators and in some cases perform voltage and frequency regulation.

4. External - can be another stable AC grid.

It is crucial that the wind generators need to be operated in power control mode, with both pitch angle and electromagnetic torque (Power control) regulated to achieve the desired power using either a lookup table based implementation or by calculations for de-loading the generator ([14], [15]). This is because, the overall load is constant in island mode and only this load (both active and reactive) has to be compensated by the source of energy.

In [16] the wind generators, equipped with additional energy storage, are said to operate in droop control mode and initially one of the wind generators is capable of powering the auxiliaries of a second wind turbine. The smoothness of wind variation is measured and desired action is taken on using the combination of energy storage and available wind energy to maintain constant power supply during black start.

In modern wind generators, Uninterrupted Power Supplies (UPS) [12] allow the wind generator to be monitored and operated for safety purposes for about 12-24 hours (12-48 hours according to [17]), to enable the wind farm island mode. They are crucial in case of long downtime of wind power plants and during extreme weather conditions to effectively safeguard and monitor the health of WGs. In [18] it is even stated that the UPS aids during the black start of the wind generator. One of the solutions available in the industry today[17], elaborates that the wind generators operate in 'Master' mode, generating the voltage and frequency to self-power their own auxiliary equipment. This enables the OWPP to remain in prolonged island mode. 
It is clear that modern wind generators have been equipped with certain additional equipment and control algorithms for security and safety and in some cases, for self-starting and island operation (as pointed out in [11]). But, in the case of DR-HVDC OWPP, to enable startup and subsequent transition to normal mode of operation, a dedicated and cost effective black start solution is indispensable.

\section{Various Solutions for the black start of the offshore AC grid}

The various solutions to be discussed in the section are illustrated in the Fig. 2. The system is assumed to contain a full bridge MMC onshore, to allow reduced HVDC voltage operation. This is required for some of the solutions and ensure system availability when one of the (multiple) series connected DR units fail.

The industrial solution for black start is the MVAC Umbilical cable, also represented in the Fig. 2. The capacity of this cable as per the illustrations presented in [19] is 50 MVA for a 1200 MW OWPP, or close to $4.2 \%$ in MVA rating, as a percentage of the nameplate capacity in MW of the OWPP. Once WGs are self-sufficient and necessary offshore equipment are energized, the umbilical is disconnected and the DR conduction is enabled for wind power extraction. In the current industrial solution, the WGs are equipped with grid forming control scheme [19].

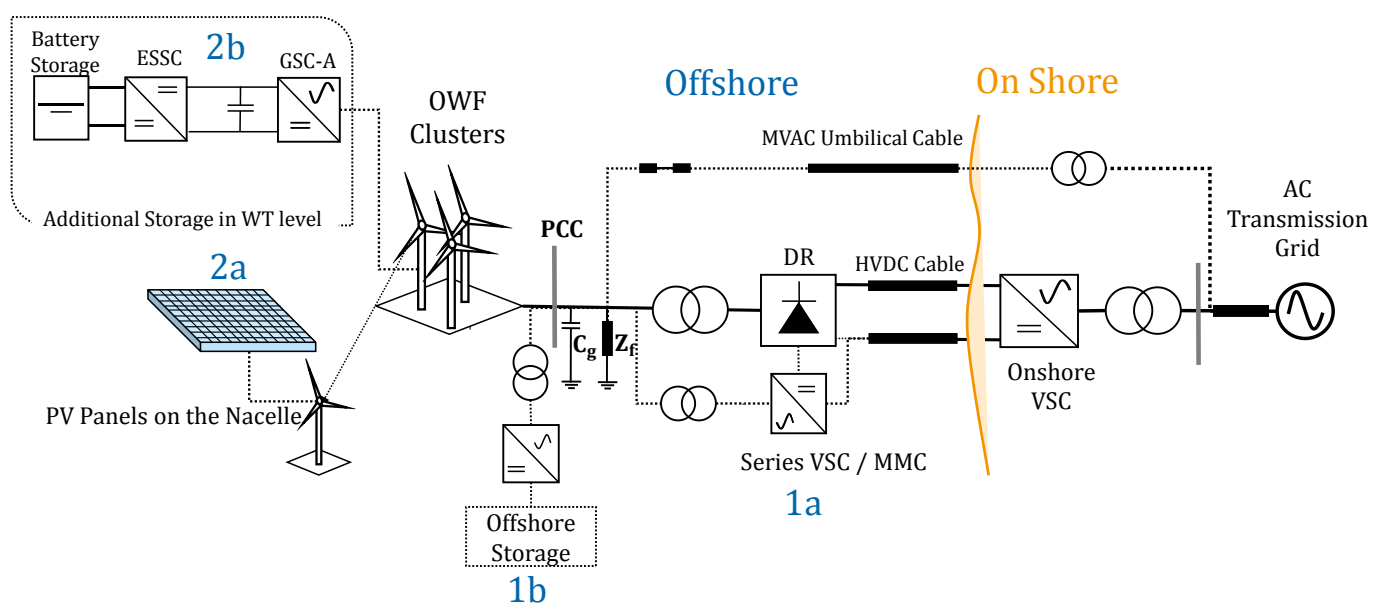

Fig. 2: Illustration of the various black start solutions discussed for DR-HVDC OWPP

During normal operation the MVAC cable is disconnected and not serving any purpose. It's operated only during black start and possibly it can be useful during prolonged island operation. Thus it is worth exploring other alternatives to the Umbilical that could provide equal reliability and at the same time be of service during a greater part of its lifetime.

The following solutions are suggested as alternatives to the AC Umbilical for black start. It is worth pointing out that depending on the solution, the WGs may or may not retain the conventional grid following control scheme (see Fig. 1). The numbered grouping $(1,2,3)$ is done to categorize the type of solution based on the following description

1. Additional VSC based solution either in series or in parallel with the system.

2. Use of additional energy source, preferable avoiding Diesel generator.

3. Using the tried and tested Diesel generator - centralized or distributed.

\section{1a. Additional VSC in series with the DR}

Solution 1a as indicated in Fig. 2 is the use of a VSC or a Modular Multilevel Converter (MMC) in series with the DR. Such configuration is analyzed in [12], [20] in a detailed manner related to system design, control schemes and cost indications. Due to bidirectional power transfer capability, the offshore VSC can now perform black start by drawing power from onshore grid for the offshore loads and auxiliaries. In this case the onshore MMC has to be of full bridge type so that the DR can be bypassed to connect the offshore MMC /VSC at reduced HVDC Voltage. The WGs may retain the grid following control scheme, because the VSC is capable of regulating the voltage and the frequency of the offshore 
AC grid. In [12], the MMC (in series with the DR) is dimensioned to a third of the total power capacity of the offshore station and also the modules used are full bridge submodules. This significantly reduces the cost advantage of the DR-HVDC due to the cost and footprint involved with installation of the MMC in the offshore platform.

\section{1b. Offshore VSC and Energy Storage Platform}

In [21] an offshore storage platform with a VSC to ensure island operation is proposed. This configuration can also be extended to perform black start of the offshore grid for the DR-HVDC OWPP, either completely or partially. The VSC could be used also to ensure grid forming of the offshore network, providing the possibility for the WGs to retain their grid following control scheme, as in a conventional VSC-HVDC connected OWPP.

\section{2a. Photovoltaic Panel installations on the Nacelle of WGs in addition to other energy source}

Another interesting proposition can be the use of Photovoltaic (PV) panels to provide a part of the required auxiliary power. In this case, no additional changes to the wind generator structure is made to install the solar panels and only the surface area available on the WG Nacelle is utilized for initial estimation.

For machines with gear box between the PMSG and the turbine like the V164-9.5 MW [22], the nacelle surface available according to the dimensions indicated should be approximately $192 \mathrm{~m}^{2}$. Considering the installations like the heli-hoist platforms for WG service needs, it is safe to assume that only half of the surface area could be available, i.e. $96 \mathrm{~m} 2$ for PV installations. Assuming a power density of 175 $\mathrm{Wp} / \mathrm{m}^{2}$ [23] for the PV panel, this available area can have an installation of $17.28 \mathrm{~kW}$ peak capacity. The factors like angle of inclination of the panel, the solar irradiance etc. and their effects on power production are not analyzed in detail at this point. But WG active power load is relatively larger compared to this capacity of PV panels that can be installed on the Nacelle surface. Assuming constant auxiliary requirement of $3 \%$ as nominal for the $10 \mathrm{MW} \mathrm{WG}$, the power requirement for self-sufficient operation is around $300 \mathrm{~kW}$ of constant load. Thus, alternate energy source / wind power has to be used during the black start, with the solar PV acting playing a minor role in auxiliary supply (possible assist in pitch or yaw actions).

\section{2b. Additional energy storage at WG level}

As pointed out, dedicated UPS systems exist at WG level to provide standby power. Additional battery storage could be required to maintain the WGs operational beyond a certain duration. Thus it could be a good approach to design additional energy storage system to ensure the black start operation at WG level. Two different configurations of energy storage integration can be used for this purpose, as shown in the Fig. 3, based on the review of existing solutions.

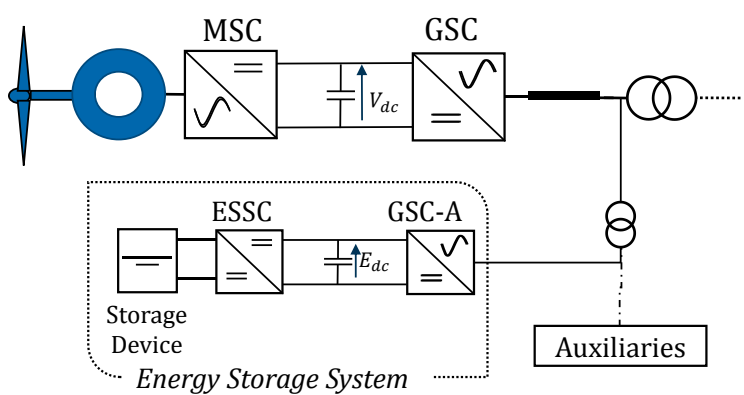

(a)

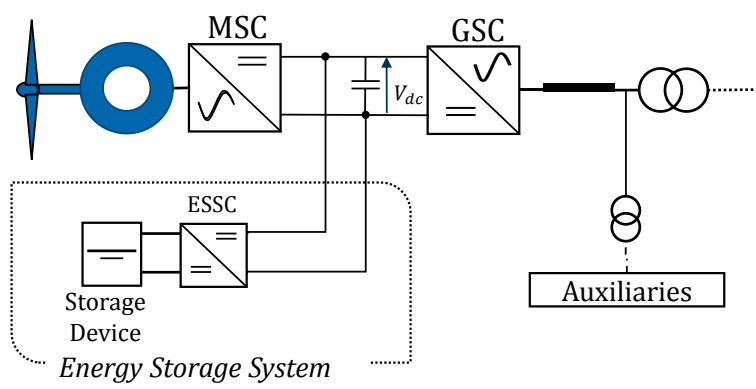

(b)

Fig. 3 : Integration of Energy Storage Device in the WG (a) On the AC side (b) In the DC link of the WG converters

In Fig. 3 (a), the storage device is connected to a DC -DC converter, indicated as the Energy Storage Side Converter (ESSC) and the auxiliaries can be powered through the Grid Side Converter for Auxiliaries (GSC-A). In this case the DC link can be energized, for instance by the antiparallel diodes of the IGBTs in the GSC or by controlling the main GSC for DC voltage control function. Once the DC link is charged, the MSC can regulate this DC bus voltage using the control scheme defined, for instance 
in [2]. In Fig. 3 (b), the ESSC is connected directly to the DC link and the auxiliaries are supported using a GSC-A connected to the storage device.

In both cases ( $\mathrm{a}$ and $\mathrm{b}$ ) advanced control functions like power smoothing can also be integrated, so that the storage sized for black start requirement is also used throughout normal operation. The choice of a particular configuration (between a and b) can be made based on cost considerations, sizing capabilities of existing storage systems for a given WG manufacturer, available space in the WG platform, among others.

The Table 1 presents a summary of the discussions in addition to the solution with Diesel Generator (numbered as solution 3) - which could be either mobile or stationary, installed in a dedicated platform and/or placed in each of the WGs. The choice of a particular black start solution has to be made considering the economic factors involved apart from the technical feasibility.

Table 1. Summary of different solutions for black starting the OWPP

\begin{tabular}{|c|l|l|l|l|l|l|}
\hline No & Type & $\begin{array}{l}\text { Energy } \\
\text { Source }\end{array}$ & \multicolumn{1}{|c|}{ Comments } & \multicolumn{1}{c|}{$\begin{array}{c}\text { Control of WG } \\
\text { Converters }\end{array}$} & \multicolumn{1}{|c|}{ Advantage } & Disadvantages \\
\hline 1a & $\begin{array}{l}\text { Series VSC }+ \\
\text { DRU }\end{array}$ & $\begin{array}{l}\text { HVDC / } \\
\text { onshore } \\
\text { Grid }\end{array}$ & $\begin{array}{l}\text { VSC of sizeable } \\
\text { capacity. }\end{array}$ & $\begin{array}{l}\text { Grid Following mode } \\
\text { (see Fig. 1) }\end{array}$ & $\begin{array}{l}\text { Active filtering } \\
\text { and Grid Forming } \\
\text { by VSC. }\end{array}$ & $\begin{array}{l}\text { Sizing of the VSC, } \\
\text { and cost factors for } \\
\text { VSC substation. }\end{array}$ \\
\hline 1b & $\begin{array}{l}\text { VSC offshore } \\
\text { platform }+ \\
\text { Battery }\end{array}$ & Batteries & $\begin{array}{l}\text { Dedicated VSC } \\
\text { with battery as a } \\
\text { separate platform. }\end{array}$ & Grid Following mode & $\begin{array}{l}\text { Active filtering } \\
\text { and Grid Forming } \\
\text { by VSC(feasible). }\end{array}$ & $\begin{array}{l}\text { Must Ensure charge } \\
\text { of Storage. } \\
\text { Additional platform. }\end{array}$ \\
\hline 2a & $\begin{array}{l}\text { Additional } \\
\text { energy } \\
\text { storage }\end{array}$ & Batteries & $\begin{array}{l}\text { Additional } \\
\text { Battery at WG } \\
\text { level }\end{array}$ & $\begin{array}{l}\text { Grid Forming mode } \\
\text { (see Fig. 1) }\end{array}$ & $\begin{array}{l}\text { Additional storage } \\
\text { among WGs, sizing } \\
\text { / space requirements }\end{array}$ \\
\hline 2b & $\begin{array}{l}\text { PV Panels + } \\
\text { Battery }\end{array}$ & $\begin{array}{l}\text { Photo } \\
\text { Voltaic } \\
\text { Panels }\end{array}$ & $\begin{array}{l}\text { In addition to } \\
\text { minimum battery, } \\
\text { use PV }\end{array}$ & Grid Forming mode & $\begin{array}{l}\text { Renewable } \\
\text { Energies of Wind } \\
\text { and Solar. }\end{array}$ & $\begin{array}{l}\text { Small capacity and } \\
\text { Maintenance of PV }\end{array}$ \\
\hline 3 & $\begin{array}{l}\text { Diesel Station } \\
\text { / Mobile Unit }\end{array}$ & Diesel & $\begin{array}{l}\text { Use Diesel fuel at } \\
\text { WG level or } \\
\text { additional station. }\end{array}$ & Grid Forming mode & $\begin{array}{l}\text { Tried and Tested } \\
\text { Method }\end{array}$ & $\begin{array}{l}\text { High Insurance } \\
\text { costs for Diesel [9], } \\
\text { Maintenance issues. }\end{array}$ \\
\hline
\end{tabular}

\section{Energy Requirement for Black start of OWPP}

The power requirement for performing offshore AC grid black can be estimated using the available parameters of the grid. The study case network used for calculation and further simulation studies is shown in the Fig. 4. And the corresponding parameters of the system are indicated in the Table 2. A $400 \mathrm{MW}$ wind power plant is considered for the study case and the grid forming control in [4] (Voltage and frequency regulation with PLL based Synchronization) implemented for all the wind generators. As in [4], it is assumed that the wind generators are provided with self-start capability using some form of local energy storage and thus the auxiliaries are not modelled for the simulation.

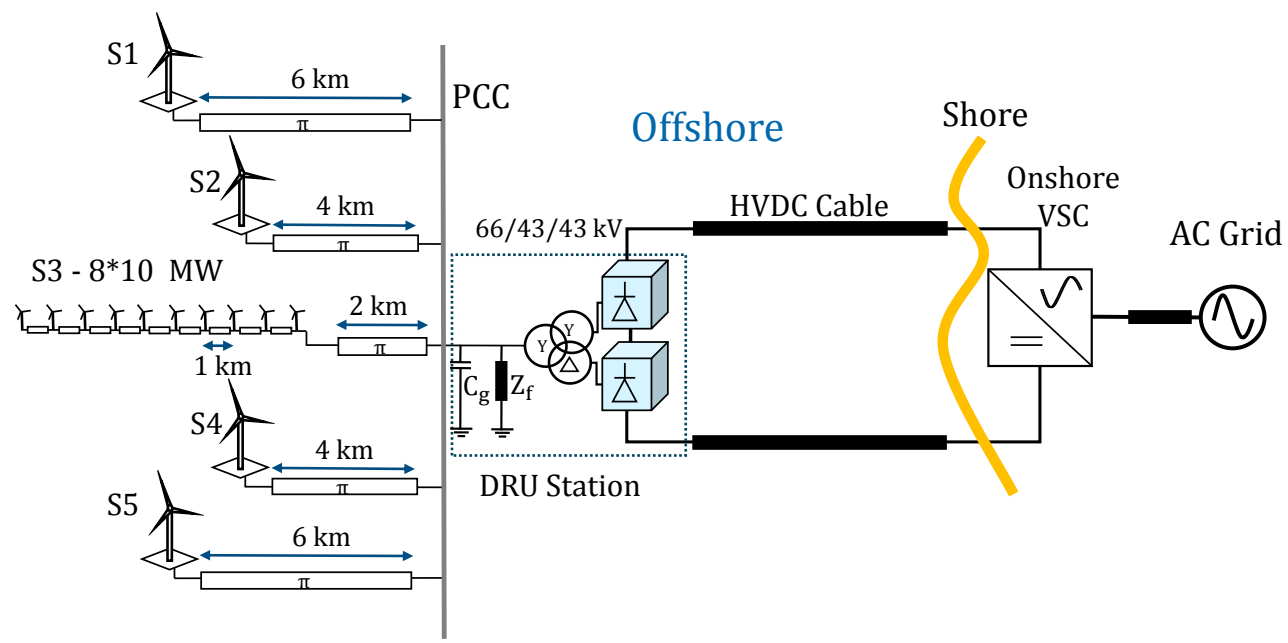

Fig. 4: OWPP Study Case Network 
The focus, of this study, is to obtain the active and reactive power requirement for energizing the offshore $\mathrm{AC}$ grid and the observations during island to normal modes of operation. The requirement of auxiliaries can be obtained from calculations for all the turbines in total.

Table 2. OWPP Simulation parameters and power calculations

\begin{tabular}{|c|c|c|}
\hline Component & Parameter & Value (Unit) \\
\hline \multirow[t]{5}{*}{$\begin{array}{l}\text { Wind Turbine } \\
\text { String }\end{array}$} & $\begin{array}{l}\text { Rated Power of considered unit } \\
\text { turbine (string S3) }\end{array}$ & $8 \mathrm{MW} * 10 \rightarrow 80 \mathrm{MW}$ \\
\hline & Transformer & $690 \mathrm{~V} / 66 \mathrm{kV} ; \mathrm{X}_{\mathrm{L}}=0.03 \mathrm{pu}$ \\
\hline & Filter R, L, C & $0.0012 \mathrm{pu} ; 0.3 \mathrm{pu} ; 0.1 \mathrm{pu}$ \\
\hline & VSC Model Type & Average Model \\
\hline & GSC Control & Distributed V,f control with PLL based Synchronization[4] \\
\hline \multirow{6}{*}{$\begin{array}{l}\text { Offshore Wind } \\
\text { Power Plant }\end{array}$} & Rated Power Capacity & $400 \mathrm{MW}$ \\
\hline & Offshore Transformer & $66 \mathrm{kV} / 43 \mathrm{kV} / 43 \mathrm{kV}$ \\
\hline & Diode Rectifier Unit & 12 Pulse Full Bridge \\
\hline & Offshore Capacitor $\left(\mathbf{C}_{\mathbf{g}}\right)$ & $2.5 \mu \mathrm{F}$ \\
\hline & Offshore Filter Bank $\left(\mathbf{Z}_{\mathrm{f}}\right)$ & $0.2 \mathrm{pu}$ (reactive power); \\
\hline & $\begin{array}{l}\text { Submarine Cables (length }=1 \mathrm{~km} \\
\text { between WGs) }\end{array}$ & $\mathrm{R}=0.1 \Omega ; \mathrm{L}=0.366 \mathrm{mH} ; \mathrm{C}=0.224 \mu \mathrm{F}$ \\
\hline \multirow{4}{*}{$\begin{array}{l}\text { Active and Reactive } \\
\text { Power Requirement } \\
\text { (at } 0.8 \text { pu Voltage } \\
\text { in Island mode) }\end{array}$} & String level $-\mathrm{S} 3$ & $\mathrm{P}=0.6 \mathrm{~kW}$ (negligible); $\mathrm{Q}=-2.16 \mathrm{MVAr}$ \\
\hline & Collection Network -5 strings & $\mathrm{P} \sim=0.8 \mathrm{MW}$ (transformer); $\mathrm{Q}=-14.12 \mathrm{MVAr}$ \\
\hline & $\begin{array}{l}\text { Auxiliary Supplies for WGs in } \\
\text { String ( } 3 \% \text { of MW per WG) }\end{array}$ & 2.4 MW; 1.16 MVar (pf=0.9) \\
\hline & Auxiliary supply for all WGs & $12 \mathrm{MW} ; 5.82 \mathrm{MVar}(\mathrm{pf}=0.9)$ \\
\hline
\end{tabular}

The observations from the study and the energy requirement calculations, permit assessing the above discussed solutions for black start. A few simulation results are presented to highlight the reactive power demand in the network, as and when the WGs and the strings are interconnected. In Fig. 5 it is seen that the WGs in string 3 are connected in a sequential manner and they share voltage and frequency regulation using the afore mentioned [10] grid forming scheme. It is assumed that at the initial time, all the WGs are disconnected from the string and the strings are disconnected from the PCC (associated breakers are open). The offshore filter $\left(\mathbf{Z}_{\mathbf{f}}\right)$ is also not connected to the PCC. The WG1 inverter is first connected to the string (S3) by closure of its breaker and thus it has to compensate the reactive power load of the submarine cables in the entire string, until the PCC (negative, Q absorption by the inverters). So correspondingly, from 2.5 to $3 \mathrm{~s}$, there is negative demand in reactive power close to $2 \mathrm{MVAr}$, until the WG2 is connected to the string (this requirement is close to the calculated value of - 2.16 MVAr as seen in the Table 2). Now WG1 and WG2 operate in droop control, regulating voltage and frequency, and sharing the reactive power demand of the network (which is the string). Thus as each WG is connected to the string from $3 \mathrm{~s}$ to $7 \mathrm{~s}$, the reactive power contribution is shared by more WGs and thus a gradual reduction in the reactive power contribution by each WG is seen.

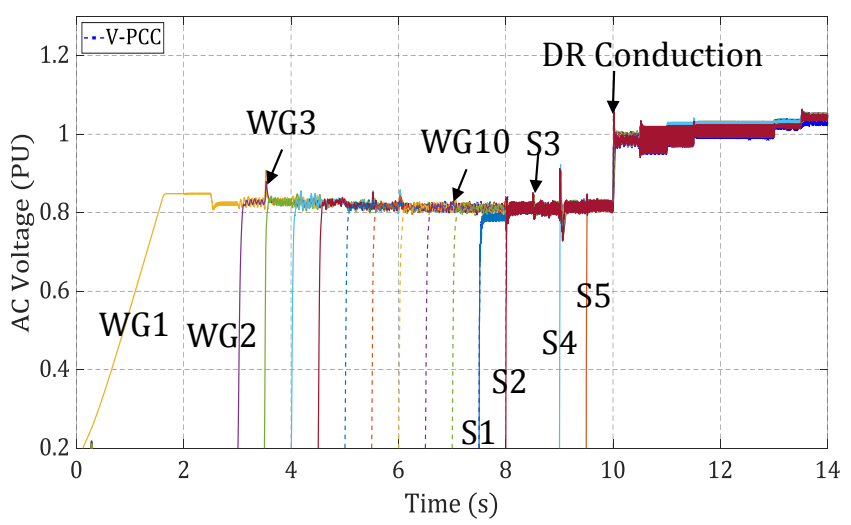

Fig. 5: AC Voltage at WG terminals and strings 
At $7.5 \mathrm{~s}$, one of the strings $\mathrm{S} 1$ (modelled as an aggregated WG of an entire string) is connected to the PCC (as seen by increase of voltage in Fig. 5) and as a result there is a provision of the offshore transformer losses close to $0.8 \mathrm{MW}$ (seen in Fig. 6). The other component of the active power losses in the network is calculated using the submarine cable resistance (Table 2) and is shown to be very small. The major active power load of the entire system, is the WG auxiliaries and the transformer losses (which works out to a total of $12.8 \mathrm{MW}$ ).
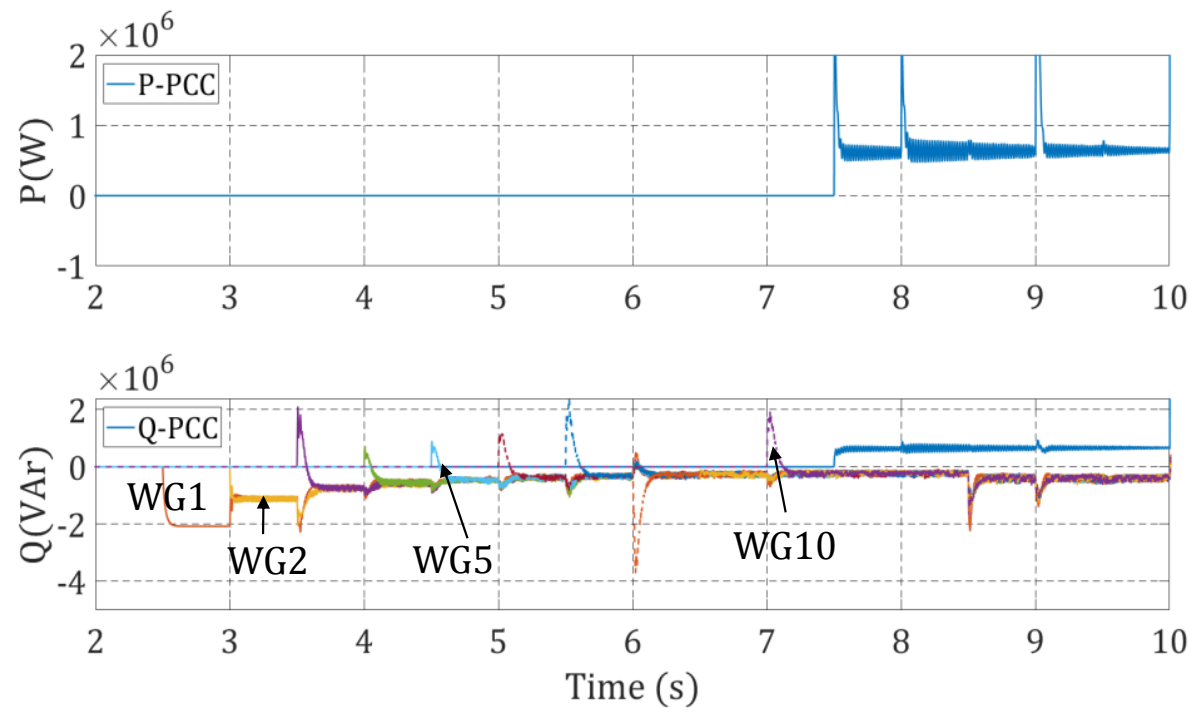

Fig. 6: Active Power load at PCC and reactive power contribution by WGs

\section{Results and Discussions}

It is worth noticing that the island offshore grid impedance is predominantly capacitive. And thus the initial charging current is to compensate or absorb the reactive power injection by the collection network cables. The offshore filter of $80 \mathrm{MVAr}$ is connected after DR conduction (higher power output). Of the solutions compared in the section II, two of the solutions are compared further, given that the solutions $1 \mathrm{a}, 2 \mathrm{~b}$ have potential disadvantages in costs and that the motive has been to find an alternative to the Diesel generator (Solution 3 in Table 1).

1. The solution 1b with VSC and dedicated storage, has to be designed for the compensation of the offshore active power losses (12.8 MW, considering WG auxiliaries also) and to charge the network (-14.12 MVAr but can be less based on inductive loads considered). This active power requirement of $12.8 \mathrm{MW}$, is when the UPS systems are incapable of self-powering the auxiliaries of the WGs after a prolonged down time of the plant. The VSC could be sized for peak apparent power rating ( $\sim 19.05 \mathrm{VA}$ ). But investigation has to be done if the WGs can retain their grid following scheme or if there are additional control changes required, to ensure stable operation (i.e. island, connected, fault cases and various transitions between modes). Here the solution is a single point of failure and an alternative in case of VSC platform / ESS failure may have to be ensured.

2. The solution 2a with local storage at WG level, has to be designed for each WG corresponding to its auxiliary power requirement. Additional sizing can be done to allow the energy storage to participate in power control objectives with the WG. In this case the controlled wind generation (active power) may be used to compensate the active power losses in the offshore grid and transformer. But this requires a coordinated control of the WGs in grid forming mode along with more communication (than solution 1b) between the WGs and the OWPP controller, to manage the black start. And with larger nameplate capacity (of WGs) means fewer WGs to coordinate in the future OWPPs. But other factors, like failure of a sequence during black start, loss of communication with some WGs, etc., among others, also need to be taken into account when designing the solution (i.e. it is not simply a MW \& MWh problem).

In both cases the selection and sizing of Energy Storage System (ESS) depends on a certain duration to ensure stable black start and transition to connected mode (DR conduction mode). A quick comparison 
of design requirements to compensate various offshore network loads, for the solutions $1 \mathrm{~b}$ and $2 \mathrm{a}$ is presented in the Table 3 to sum up the above discussions. It indicates which source of energy (or inverter) is responsible for which part of the OWPP energization. For both solutions, distinction is done between the best case where the UPS is available at WG level for self-start and the worst case, when the UPS have discharged, for instance due to prolonged downtime. The 'With UPS' category for each case means the UPS is available to power WG auxiliaries during the black start process. For Solution 2a, the 'failed UPS' case means that dedicated ESS is installed in each WG as a redundancy measure for the worst case when UPS of WGs get discharged completely.

Table 3. Comparison of design requirements for solutions $1 \mathrm{~b}$ and $2 \mathrm{a}$ for different cases

\begin{tabular}{|l|c|c|c|c|}
\hline Offshore Load Type & $\begin{array}{c}\text { 1b } \\
\text { (with UPS) }\end{array}$ & $\begin{array}{c}\text { 1b } \\
\text { (UPS failed) }\end{array}$ & $\begin{array}{c}\text { 2a } \\
\text { (with UPS) }\end{array}$ & $\begin{array}{c}\text { 2a } \\
\text { (UPS Failed) }\end{array}$ \\
\hline $\begin{array}{l}\text { WG Auxiliaries } \\
(12 \mathrm{MW} ; 5.82 \text { MVar) }\end{array}$ & UPS & $\begin{array}{c}\text { Additional } \\
\text { VSC - ESS }\end{array}$ & UPS & $\begin{array}{c}\text { Additional } \\
\text { ESS }\end{array}$ \\
\hline $\begin{array}{l}\text { Offshore Transformer } \\
(0.8 \mathrm{MW})\end{array}$ & VSC - ESS & VSC - ESS & WG & WG \\
\hline $\begin{array}{l}\text { Collection Network } \\
(-14.12 \mathrm{MVAr})\end{array}$ & VSC - ESS & VSC - ESS & WG & WG \\
\hline
\end{tabular}

\section{Conclusion}

In this paper, the various challenges related to the black start of the offshore AC grid for a DR-HVDC based OWPP have been briefly discussed. Following this, some of the solutions that can enable the black start have been presented. The motivation is to reduce or eliminate the use of Diesel as the primary source for the black start and also to explore other options, which could be interesting and reliable compared to the MVAC Umbilical cable (industrial solution).

The power requirement for the offshore grid island mode is highlighted using a study case network. Two of the black start solutions are assessed further, based on the power requirements and possible constraints/ capabilities. Although the exact energy requirement could not be deduced, it is safe to assume that the time duration from black start until the transition to normal operation, plays a crucial role in sizing the selected solution, for energy (Wh). Further decision on the exact solution could be taken by approaches, similar to [24] considering techno economic factors at the system level, with acceptable level of cost modelling.

Future studies could be focused on determining the impacts on the wind turbine (the mechanical drive train) due to the grid forming and de-loading control functions by the GSC and the capability of a chosen black start solution to reduce or alleviate any dire impacts. Also there is a need to perform cost comparison studies for the design of each black start solution, to allow a suitable decision in a given OWPP project. A suitable black start solution, could not only aid in rendering the DR-HVDC OWPP technology cheaper and more reliable, but also allow the OWPPs to play further role in power system restoration of the onshore grid.

\section{Bibliography}

[1] Peter Menke, "New grid access solutions for offshore wind farms," EWEA Offshore 2015, 2015.

[2] R. Blasco-Gimenez, S. Añó-Villalba, J. Rodríguez-D’Derlée, F. Morant, and S. Bernal-Perez, "Distributed Voltage and Frequency Control of Offshore Wind Farms Connected With a Diode-Based HVdc Link," IEEE Trans. Power Electron., vol. 25, no. 12, pp. 3095-3105, Dec. 2010.

[3] C. Prignitz, H. G. Eckel, S. Achenbach, F. Augsburger, and A. Schön, "FixReF: A control strategy for offshore wind farms with different wind turbine types and diode rectifier HVDC transmission," in 2016 IEEE 7th International Symposium on Power Electronics for Distributed Generation Systems (PEDG), 2016, pp. 1-7.

[4] L. Yu, R. Li, and L. Xu, "Distributed PLL-Based Control of Offshore Wind Turbines Connected With Diode-Rectifier-Based HVDC Systems," IEEE Trans. Power Deliv., vol. 33, no. 3, pp. 1328-1336, Jun. 2018.

[5] R. Ramachandran, S. Poullain, A. Benchaib, S. Bacha, and B. Francois, “AC Grid Forming by Coordinated Control of Offshore Wind Farm connected to Diode Rectifier based HVDC Link - Review 
and Assessment of Solutions," in 2018 20th European Conference on Power Electronics and Applications (EPE'18 ECCE Europe), 2018, p. P.1-P.10.

[6] S. Bernal-Perez, S. Ano-Villalba, R. Blasco-Gimenez, and J. Rodriguez-D’Derlee, "Efficiency and Fault Ride-Through Performance of a Diode-Rectifier- and VSC-Inverter-Based HVDC Link for Offshore Wind Farms," IEEE Trans. Ind. Electron., vol. 60, no. 6, pp. 2401-2409, Jun. 2013.

[7] R. Li, L. Yu, L. Xu, and G. P. Adam, "DC Fault Protection of Diode Rectifier Unit Based HVDC System Connecting Offshore Wind Farms," presented at the 2018 IEEE Power \& Energy Society General Meeting, 2018, pp. 1--5.

[8] R. Li, L. Yu, and L. Xu, "Offshore AC Fault Protection of Diode Rectifier Unit Based HVDC System for Wind Energy Transmission," IEEE Trans. Ind. Electron., vol. 2, no. 7, pp. 5289--5299, 2018.

[9] European Commission, "A policy framework for climate and energy in the period from 2020 to 2030," European Commission, Brussels, Jan. 2014.

[10] ENTSO-E, "ENTSO-E Network Code for Requirements for Grid Connection Applicable to all Generators." [Online]. Available: https://www.entsoe.eu/fileadmin/user_upload/_library/resources/RfG/130308_Final_Version_NC_RfG.pd f. [Accessed: 05-Dec-2018].

[11] Ö. Göksu, O. Saborío-Romano, N. A. Cutululis, and P. Sørensen, "Black Start and Island Operation Capabilities of Wind Power Plants," presented at the 16th Wind Integration Workshop, Berlin, Germany, 2017, p. 4.

[12] M. von Hofen, D. Karwatzki, L. Baruschka, and A. Mertens, "Hybrid offshore HVDC converter with diode rectifier and Modular Multilevel Converter," in 2016 IEEE 7th International Symposium on Power Electronics for Distributed Generation Systems (PEDG), 2016, pp. 1-7.

[13] A. Jain and K. Das, "Control Solutions for Blackstart Capability and Islanding Operation of Offshore Wind Power Plants," p. 7, 2018.

[14] J. L. Rodríguez-Amenedo, S. Arnalte, and J. C. Burgos, "Automatic Generation Control of a Wind Farm With Variable Speed Wind Turbines," IEEE Trans. ENERGY Convers., vol. 17, no. 2, p. 6, 2002.

[15] R. G. deAlmeida, E. D. Castronuovo, and J. A. PecasLopes, "Optimum Generation Control in Wind Parks When Carrying Out System Operator Requests,” IEEE Trans. Power Syst., vol. 21, no. 2, pp. 718-725, May 2006.

[16] X. Huang and Y. Chen, "Method for black starting wind turbine, wind farm, and restoring wind farm and wind turbine, wind farm using the same," US20170074244A1, 16-Mar-2017.

[17] ABB, "Technical note ABB medium voltage wind turbine converters enable island mode operation." [Online]. Available:

https://library.e.abb.com/public/dee1542f16c66b39c1257d2d00284d9a/PCS6000\%20technical\%20note is land\%20mode_lowres.pdf.

[18] P. Egedal, S. Kumar, and K. S. Nielsen, "Black start of wind turbine devices," US9509141B2, 29-Nov2016.

[19] T. Hammer, S. Seman, and P. Menke, "Diode-Rectifier HVDC link to onshore power systems: Dynamic performance of wind turbine generators and Reliability of liquid immersed HVDC Diode Rectifier Units," CIGRE 2016, vol. B4-121.

[20] T. H. Nguyen, D. C. Lee, and C. K. Kim, "A Series-Connected Topology of a Diode Rectifier and a Voltage-Source Converter for an HVDC Transmission System," IEEE Trans. Power Electron., vol. 29, no. 4, pp. 1579-1584, Apr. 2014.

[21] N. Kouassi and B. Francois, "AC offshore grid forming of a collection network for wind park by considering storage and hybrid power electronic systems," in 2016 International Conference on Electrical Sciences and Technologies in Maghreb (CISTEM), 2016, pp. 1-9.

[22] M. Vestas, "Innovations | Offshore Wind Turbines | MHI Vestas ${ }^{\mathrm{TM}}, "$ MHI Vestas Offshore. [Online]. Available: http://www.mhivestasoffshore.com/innovations/. [Accessed: 11-Jul-2017].

[23] N. T. Ave, "Datasheet for Panasonic HIT Power 220A." [Online]. Available: http://www.panasonic.com/business/pesna/includes/pdf/eco-constructionsolution/HIT_Power_220A_Datasheet.pdf.

[24] S. Gasnier, V. Debusschere, S. Poullain, and B. François, "Technical and economic assessment tool for offshore wind generation connection scheme: Application to comparing $33 \mathrm{kV}$ and $66 \mathrm{kV}$ AC collector grids authors," in 2016 18th European Conference on Power Electronics and Applications (EPE'16 ECCE Europe), 2016, pp. 1-8. 